University of Nebraska - Lincoln

DigitalCommons@University of Nebraska - Lincoln

Educational Psychology Papers and

Publications

Educational Psychology, Department of

2008

\title{
The Effectiveness of a Partnership-Centered Approach in Conjoint Behavioral Consultation
}

\author{
S. Andrew Garbacz \\ University of Nebraska-Lincoln, andy.garbacz@wisc.edu \\ Kathryn E. Woods \\ University of Nebraska-Lincoln \\ Michelle S. Swanger-Gagné \\ University of Nebraska-Lincoln \\ Ashley M. Taylor \\ University of Nebraska-Lincoln \\ Kathryn A. Black \\ University of Nebraska-Lincoln
}

See next page for additional authors

Follow this and additional works at: https://digitalcommons.unl.edu/edpsychpapers

Part of the Educational Psychology Commons

Garbacz, S. Andrew; Woods, Kathryn E.; Swanger-Gagné, Michelle S.; Taylor, Ashley M.; Black, Kathryn A.; and Sheridan, Susan M., "The Effectiveness of a Partnership-Centered Approach in Conjoint Behavioral Consultation" (2008). Educational Psychology Papers and Publications. 83.

https://digitalcommons.unl.edu/edpsychpapers/83

This Article is brought to you for free and open access by the Educational Psychology, Department of at DigitalCommons@University of Nebraska - Lincoln. It has been accepted for inclusion in Educational Psychology Papers and Publications by an authorized administrator of DigitalCommons@University of Nebraska - Lincoln. 


\section{Authors}

S. Andrew Garbacz, Kathryn E. Woods, Michelle S. Swanger-Gagné, Ashley M. Taylor, Kathryn A. Black, and Susan M. Sheridan 

published in the APA journal. It is not the copy of record."

This study was funded by grants awarded to Susan M. Sheridan by the U.S. Department of Education, Office of Special Education Programs. The comments and opinions presented are those of the authors and do not reflect official positions or policies of the granting agency. Appreciation is extended to Carrie Blevins, Jennifer Burt, Brandy Clarke, Brett Foley, Katie Magee, Diane Marti, Stephanie Olson, and Michael Toland for assisting in the compilation of data for this project.

\title{
The Effectiveness of a Partnership-Centered Approach in Conjoint Behavioral Consultation
}

\author{
S. Andrew Garbacz, Kathryn E. Woods, Michelle S. Swanger-Gagné, \\ Ashley M. Taylor, Kathryn A. Black, and Susan M. Sheridan \\ Department of Educational Psychology, University of Nebraska-Lincoln \\ Corresponding author - S. Andrew Garbacz, Department of Educational Psychology, 114 Teacher's College Hall, \\ University of Nebraska-Lincoln, Lincoln, NE 68588-0345, email sagarbacz@yahoo.com
}

\begin{abstract}
The purpose of this exploratory study was to investigate the extent to which a partnership orientation in conjoint behavioral consultation (CBC) may predict case outcomes and determine the relationship between a partnership orientation and implementation integrity of $\mathrm{CBC}$. СBC is a problem-solving process by which families and teachers work collaboratively with a consultant to address students' academic, behavioral, and social needs. Twenty children, their parents and teachers, and consultants were involved in CBC services. Outcomes included parent and teacher ratings of acceptability, satisfaction, perceptions of effectiveness, and child performance across home and school settings. Partnership orientation scores and process integrity data were collected across interviews for each case. Results suggest that both parents and teachers consistently find CBC to be an acceptable, effective, and satisfactory form of service delivery. Findings reveal that consultants can conduct $C B C$ interview objectives effectively within a partnership orientation. A partnership orientation in $\mathrm{CBC}$ was significant in predicting teachers' acceptability and satisfaction with the process; however, parents' acceptability and satisfaction with the CBC process was not predicted by a partnership orientation.
\end{abstract}

Keywords: conjoint behavioral consultation, families, schools, family-school partnerships

A multitude of learning opportunities and experiences for children exists within and across multiple settings, such as home and school. Families and schools are two systems whereby individuals are in a position to uniquely and collectively contribute to children's development and educational success (Christenson \& Sheridan, 2001). Both families and schools provide supportive settings in which children develop and learn (Christenson, Rounds, \& Franklin, 1992). Whereas learning within schools is widely recognized, opportunities to support learning in the home must also be acknowledged, and means to facilitate out of school experiences warrant further attention.

Families are a constant factor contributing to children's overall development and educational success.
Families are socializing agents who support the acquisition of numerous developmental skills necessary for children's future success in school (Adams \& Christenson, 2000; Sheridan, Eagle, \& Dowd, 2005) and are in a unique position to provide learning and enrichment opportunities for children within a natural environment. Family process variables associated with children's achievement include the verbal environment of the home, parental expectations, warmth/nurturance, control, and beliefs/attributions (Hess \& Holloway, 1984). These family process variables represent characteristics of what Walberg (1984) coined "curriculum of the home," which constitutes direct and indirect ways families can promote their child's learning out of school. Indeed, the natural environment of the home, more than any 
other isolated environment, determines a child's level of academic achievement, interest in school, and the number of years he or she will remain in school (Kellaghan, Sloane, Alvarez, \& Bloom, 1993). Given the powerful effects of families' contributions to children's achievement and educational success, facilitating methods for and promoting family school partnerships remain a high priority.

The framework for a partnership-centered approach promotes strengths and skill building within families and school personnel by identifying and accessing resources for both parties. As such, intervention models that infuse and promote a partnership orientation may influence outcomes experienced as a function of that intervention. A partnership orientation is counter to one focusing on the sole identification of problems or remediation of deficiencies within the child or an isolated system (Sheridan, Warnes, Cowan, Schemm, \& Clarke, 2004). A partnership approach originates from the assumption that "child and family outcomes will be enhanced if members participate in identifying needs, establishing social supports and partnerships, and acquiring new skills and competencies, rather than simply receiving services from professionals" (Sheridan et al., 2004, pp. 7). A partnership approach promotes joint responsibilities (empowerment), individual strengths and competencies, and communication between families and school personnel. Consequently, identifying empirically supported partnership-centered approaches are warranted to facilitate the competencies and collaborative efforts between families and schools in promoting developmental and educational success of children.

Conjoint behavioral consultation (CBC) is an evidence-based consultation model that promotes collaborative and responsive efforts between families and schools to meet the academic, behavioral, and social needs of children (Guli, 2005; Sheridan, Eagle, Cowan, \& Mickelson, 2001). CBC is a structured, indirect model of service delivery in which families and teachers join in a problem-solving process to address students' academic, behavioral, and social needs (Sheridan \& Kratochwill, 2008). The goals of CBC are threefold: to address students' needs through evidence-based intervention procedures, to promote parent engagement and involvement in learning, and to build relationships and facilitate partnerships across families and schools (Sheridan, Clarke, \& Burt, 2008; Sheridan \& Kratochwill, 2008).
These goals are met in four stages wherein principles of applied behavioral analysis are translated into specific procedural steps and delivered in the context of a collaborative relationship between families, teachers, and consultants.

The stages that comprise the $\mathrm{CBC}$ process are Conjoint Needs Identification, Conjoint Needs Analysis, Plan Implementation, and Conjoint Plan Evaluation. Stages are further operationalized, in part, through structured interviews. The Conjoint Needs Identification Interview (CNII) is procedurally defined by prioritizing and defining a primary student need, or concern, and by developing procedures for collecting behavioral information about the prioritized need. During the Conjoint Needs Analysis Interview (CNAI), the consultant, family members, and teachers set goals for the student based on the behavioral information gathered during the needs identification stage; analyze conditions surrounding the observed behavior; and develop a plan to be implemented at home and school. Families and teachers co-implement the plan, which is then evaluated based on student progress discussed during the Conjoint Plan Evaluation Interview (CPEI). Partnerships are promoted within these interviews by building shared responsibility for students' learning and development, utilizing a strengths-based orientation, and enhancing families' and teachers' skills and relationships.

Previous research has investigated student outcomes of the CBC process and the partnership-oriented goals embedded within the process. CBC has been identified as an evidence-based consultation model that is effective in addressing students' academic, behavioral, and social needs (Guli, 2005; Sheridan et al., 2001). The positive effects of CBC have been documented in regard to several student needs including homework completion and accuracy (Galloway \& Sheridan, 1994; Weiner, Sheridan, \& Jenson, 1998), externalizing and internalizing behavior problems (Illsley \& Sladeczek, 2001; Kratochwill, Elliott, Loitz, Sladeczek, \& Carlson, 2003), social skill development (Colton \& Sheridan, 1998; Sheridan, Kratochwill, \& Elliott, 1990), compliance (Ray, Skinner, \& Watson, 1999), anxiety (Sheridan \& Colton, 1994), and behavioral control (Wilkinson, 2005). CBC has also been reported to be an acceptable model of service delivery by school psychologists, parents, and teachers (Sheridan \& Steck, 1995; Sladeczek, Madden, Illsley, Finn, \& August, 2006). 
Studies suggesting the presence of partnershiporiented principles in CBC have focused on collaboration and partnership orientation throughout the $\mathrm{CBC}$ process. In $\mathrm{CBC}$ meetings, the vast majority of verbal statements and exchanges made by consultants, families, and teachers have been found to be collaborative in nature (Sheridan, Meegan, \& Eagle, 2002). Although general principles of "effective helping" are present in CBC (i.e., "the act of enabling individuals or groups to become better able to solve problems, meet needs, or achieve aspirations by promoting the acquisition of competencies"; (Dunst, Trivette, \& Deal, 1994, p. 162), families and teachers who participate in CBC have been found to hold different perspectives on what effective helping entails (Sheridan et al., 2004). Consequently, it is important to understand each perspective in the helping process (Sheridan et al., 2004).

More recently, an exploratory, descriptive study examined consultants' effectiveness in conveying a partnership-orientation throughout the CBC process. The Partnership Orientation Measure (POM; Sheridan, Marti, et al., 2005) was developed to measure partnership orientation themes within CBC. Themes on the POM include focusing on strengths, teaming and collaboration, being sensitive and responsive, communicating effectively, developing skills, and being resourceful and sharing information. Preliminary research conducted by the present authors indicated that the majority of consultants in the sample were generally effective in conveying a partnership-oriented tone (Sheridan, Marti, et al., 2005).

Despite the demonstrated, positive outcomes associated with $\mathrm{CBC}$ and the potential of $\mathrm{CBC}$ as a model that actively encourages partnerships, the degree to which a partnership approach predicts subsequent case outcomes in $\mathrm{CBC}$ has not been studied. In addition, the degree to which consultants can deliver the empirically supported procedural objectives of CBC within a partnership orientation (i.e., while actively attempting to forge family school connections) has not been investigated. The purposes of the current study were to investigate the degree to which a partnership orientation in CBC predicts case outcomes and to determine the relationship between a partnership orientation and $\mathrm{CBC}$ implementation integrity. Specifically, the research questions examined in this study were (a) Does a partnership orientation predict $\mathrm{CBC}$ case outcomes? and (b) What is the relationship between a partnership orientation and the implementation integrity of the $\mathrm{CBC}$ process? It was hypothesized that a partnership orientation would predict case outcomes in a positive, linear fashion. It was expected that a focus on partnership might decrease consultants' abilities to adhere to the problem-solving format; thus, it was further hypothesized that a negative relationship between partnership orientation and CBC implementation integrity would exist.

\section{Method}

The current study represents a subset of a larger, multiyear CBC study conducted in a suburban Midwestern city. CBC cases conducted between 1998 and 2005 that contained complete demographic, consultation, and postconsultation data were eligible for selection. Numerous outcomes were assessed from these cases including client behavior change and social validity (i.e., process acceptability). A power analysis was conducted to determine an adequate sample size to detect a significant effect. Eighty percent power was assumed to find large effects with one-tailed analyses. Using G*Power (Erdfelder, Faul, \& Buchner, 1996), a sample size of 20 cases was determined to be adequate to find significant results if they existed. Twenty cases were then randomly selected and used in this investigation.

\section{Participants}

Demographic information for all participants are presented in Table 1. This includes information for consultants, parents, and teachers.

\section{Demographic Characteristics of Participants}

Consultants. Consultants were 19 graduate students in a school psychology program at a major Midwestern university who were learning the principles and procedures of $\mathrm{CBC}$. One consultant was involved in two cases that were used in this investigation. Eightynine percent were women and $85 \%$ were White. The mean age of consultants was 25.80 years (range 22 to 40 years; $S D=5.22$ ). Fifty-six percent held bachelor's degrees and $44 \%$ held masters degrees at the time of consultation. Six consultants had not completed any 
Table 1. Demographic Characteristics of Participants

\begin{tabular}{lcccc}
\hline & Consultant & Parent & Teacher & Child \\
\hline Gender & & & & \\
$\quad$ Male & $11 \%$ & $10 \%$ & $15 \%$ & $75 \%$ \\
$\quad$ Female & $89 \%$ & $90 \%$ & $85 \%$ & $25 \%$ \\
Average age & 25.80 & 36.94 & 40.77 & 8.45 \\
SD & 5.22 & 9.65 & 8.24 & 4.05 \\
Ethnicity & & & $70 \%$ \\
$\quad$ White & $85 \%$ & $80 \%$ & $15 \%$ & \\
$\quad$ African American & $5 \%$ & $5 \%$ & $15 \%$ & 3.50 \\
$\quad$ Other & $15 \%$ & & & \\
Average grade & & $47 \%$ & $65 \%$ & \\
Degrees held & & $42 \%$ & $30 \%$ & \\
$\quad$ High school diploma & $56 \%$ & $11 \%$ & & \\
$\quad$ Bachelors & $44 \%$ & & \\
$\quad$ Masters degree & & & \\
$\quad$ PhD & & &
\end{tabular}

prior consultation cases, 10 had completed 1 to 5 cases, 1 had completed 6 to 15 cases, and 1 had completed more than 15 consultation cases.

Parents. Twenty parents participated in this study. Ninety percent were women and $10 \%$ were men. The mean age of parents was 36.94 years (range 23 to 57 years; $S D=9.65$ ). Eighty percent were White and $15 \%$ were considered to be living below the poverty line (i.e., income less than $\$ 15,000$ per year). Fortyseven percent had a high school diploma, $42 \%$ had earned a bachelor's degree, and 11\% held a doctorate. Fifty-five percent were married and $25 \%$ were single parents.

Teachers. Sixteen female and three male teachers were involved in the present study. The mean age of teachers was 40.77 years (range 26 to 53 years; SD $=8.24$ ). Ninety percent were White. Seventy-nine percent taught in general education classrooms, 5\% taught in special education settings, and 16\% taught in preschool classrooms. The mean number of years of teaching experience was 15.07 years (range 2 to 30 years; $S D=9.56$ ). Sixty-five percent of teachers had bachelor's degrees as their highest degree earned and $30 \%$ had master's degrees. Five percent of teachers had previous training in consultation and had previously participated in consultation cases. One teacher did not provide information on their demographic characteristics.

Child participants. Seventy-five percent of children were males, $25 \%$ were females. Seventy percent were
White, 10\% were African American, and 15\% were biracial. Thirty percent were disadvantaged due to their status as a racial minority (i.e., non-White). The mean age of children was 8.45 years (range 3 to 15; $S D=4.05)$ and the mean grade of children was 3.50 (range preschool through ninth grade). Twenty-five percent of children had been classified as having a disorder or disability (e.g., learning disability, behavior disorder, other health impairment). Seventy percent lived in homes with two or more adults and $80 \%$ had mothers who completed at least some college coursework.

\section{Setting}

Training for consultants in CBC occurred within a school psychology graduate program at a Midwestern university. Cases were conducted in Head Start, elementary, middle, and high school settings in the surrounding area. Eighty-five percent of cases were conducted in public schools; $15 \%$ were conducted in parochial schools. The majority of CBC interviews were conducted in classrooms of participating teachers; some were conducted in homes. Interventions were implemented across home and school settings for students who were the focus of consultation.

\section{Predictor and Outcome Variables}

The predictor variable in this investigation was consultants' use of a partnership orientation in CBC. Partnership orientation was defined as the 
effectiveness with which the consultant demonstrated a partnership orientation throughout the three CBC interviews. Outcome variables included parent and teacher ratings of acceptability, satisfaction, perceptions of effectiveness, and child behavior outcomes. Process (i.e., CBC) integrity data were also collected across interviews for each case. All variables were assessed at the conclusion of CBC casework.

\section{Measures}

POM. The POM was developed for the current study to assess the degree to which consultants demonstrated a partnership orientation throughout the CBC process. The POM is a 7-item measure completed for each CBC interview that assesses a consultant's use of a partnership orientation on a 6-point Likert scale. Ratings on this scale range from 1 to 6 , with 1 indicating that a consultant's use of a specific partnership orientation theme was totally ineffective (i.e., it could not have been worse). A rating of 6 indicated that the consultant's use of the theme was totally effective (i.e., it could not have been better). The POM was completed for each of the CBC interviews involved in this study (i.e., $n=3$ per case). Scores across three interviews were summed to yield a total partnership orientation score that ranged from 21 to 126 . For ease of interpretation, the total partnership orientation score was divided by three to yield a mean item rating for each interview. The POM scores were highly reliable across the 21 items $(\alpha=.896)$ and each interview score on the POM demonstrated high internal consistency (CNII, $\alpha=.905 ; \mathrm{CNAI}, \alpha=.913$; CPEI, $\alpha=.954$ ).

Development of the POM was based on previous literature and group consensus. Items were derived from the Family-Centered Practice Indicators (McWilliam, Maxwell, \& Sloper, 1999), Helpgiving Practices Scale (Trivette \& Dunst, 1994), and literature describing effective partnership practices within consultation (e.g., Christenson \& Sheridan, 2001; Sheridan \& Kratochwill, 2008). Based on items derived from these materials, thematic clusters of partnership-centered categories were created by coders who were graduate students in school psychology trained in family school partnership models and consultation. Different interviews and CBC cases were coded by each rater to identify the existence of exemplar consultant statements that represented partnership-oriented themes. Clusters were then compiled on a collective list, which was narrowed to seven themes based on group consensus. The identified themes were: focuses on strengths, promotes teaming and collaboration, encourages, is sensitive and responsive, uses effective communication, promotes skill development, and is resourceful and shares information. The seven partnership orientation themes, definitions for each theme, and specific skills displayed by the consultant representing each theme are shown in Appendix.

Content validity of the POM was established over two phases. First, respected sources in the family school partnership literature were reviewed and used in the construction of the scale. Second, five national experts in family school partnerships (i.e., four trainers/researchers in school psychology and special education, and one administrative practitioner with extensive leadership experience in family school practice and policy) reviewed the POM and provided ratings to reflect their impressions of the scale's validity. Specifically, the experts rated each theme of the POM in regard to its relevance in measuring a partnership orientation, and its clarity in defining the theme as presented on the POM. Finally, each expert indicated the overall representativeness of the POM and its collective themes in measuring a partnership orientation. Each dimension (i.e., relevance, clarity, and representativeness) was rated by the experts on a Likert-type scale. Ratings ranged from 1 to 4 , with a 1 indicating that, for example, a specific theme was not relevant in measuring a partnership orientation. A rating of a 4 indicated that, for example, a specific theme was very relevant in measuring a partnership orientation.

The results of the expert-reviewed process indicated that the themes of the POM were very relevant in measuring a partnership orientation with an overall mean relevancy rating of $3.94(S D=0.13)$. Results also revealed that the definitions of the themes are quite clear to very clear with a mean clarity rating of $3.28(S D=0.44)$. Finally, the mean representativeness of the POM and its collective themes as rated by the expert reviewers was $3.80(S D=0.45)$ indicating that the POM is, overall, very representative of a partnership orientation. 
$B I R S-R$. Parents' and teachers' beliefs of treatment acceptability and effectiveness were assessed using the Behavior Intervention Rating Scale-Revised (BIRS-R; Elliott \& Von Brock Treuting, 1991). The BIRS-R is commonly used in consultation research, and psychometric research on the BIRS-R has yielded three factors: Acceptability, Effectiveness, and Time to Effect. The Acceptability and Effectiveness factors were used in this investigation. The Acceptability and Effectiveness factors consist of 15 and 7 items, respectively, rated on a 6-point Likert scale, from strongly disagree to strongly agree. Elliott and Von Brock Treuting reported a total alpha coefficient of .97, and coefficients of .97 and .92 for the Acceptability and Effectiveness factors, respectively. Sheridan et al. (2001) reported an internal consistency of the BIRS-R total scale scores in a large CBC sample and found alpha coefficients of $\alpha=.95$ for teachers and $\alpha=.93$ for parents.

Reliability analyses for the BIRS-R Acceptability and Effectiveness factors were computed for parent and teacher ratings in the current study. A total alpha coefficient of .94 and .91 on the BIRS-R was obtained for teachers and parents, respectively. An alpha coefficient of .90 was obtained for both parents and teachers on the Effectiveness factor, and parents and teachers obtained alpha coefficients of .77 and .95 , respectively on the Acceptability factor.

CEF. The Consultant Evaluation Form (CEF; Erchul, 1987) was used to assess parents' and teachers' satisfaction with the consultant and the consultation process. The CEF contains 12 -items that are rated on a 7-point Likert scale, from strongly disagree to strongly agree. Items on this scale measure the degree to which consultees find consultants helpful and the consultation process effective. Early research yielded satisfactory internal consistency estimates $(\alpha=.95$; Erchul, 1987). Alpha coefficients of $\alpha=.83$ for parents and $\alpha=.89$ for teachers were found for the Sheridan et al. (2001) sample. An alpha of .89 was found for the sample used in the current study.

Parent and teacher reports of child performance. Child behavior outcomes were assessed through direct observation or collection of permanent products. These measures were collected continuously by parents and teachers throughout baseline, treatment, and follow-up phases. Direct observation data were obtained from consultees using data collection forms provided by the consultant. These forms were provided to (a) standardize observation procedures, (b) enhance training in data collection procedures, (c) increase reliability of data collection, and (d) provide permanent record of student performance (Noell, 2008). At school, 70\% of data were collected by teacher direct observation (e.g., frequency count of commands given). At home, 45\% of data were collected by parent direct observation (e.g., frequency count of the number of chores completed). No reliability data are available for these measures. Data collected via permanent products consisted of student performance information from worksheets or homework assignments. Fifteen percent of school data were collected by permanent products (e.g., weekly report cards). Data for the remaining cases were not reported by the consultant. Effect sizes were computed at the completion of each case using a "no assumptions" approach (Busk \& Serlin, 1992).

\section{CBC Objectives Checklist}

CBC objective checklists consist of $\mathrm{CBC}$ interview objectives commensurate with each $\mathrm{CBC}$ interview, as listed on CBC structured interview forms (Sheridan, Kratochwill, \& Bergan, 1996). Checklists were used to measure $\mathrm{CBC}$ process integrity across cases and included all CBC interviews (i.e., CNII, CNAI, CPEI) within each case. Examples of CBC objectives coded on the checklists were: defined the problem in behavioral terms (CNII), identified setting events and ecological conditions that could impact the behavior (CNAI), and determined the effectiveness of the intervention plan (CPEI). Independent observers listened to audiotaped interviews to assess the degree to which consultants implemented the CBC model and its procedures. Each item was dichotomously scored to determine if each CBC objective was met across home and school environments.

\section{CBC Consultation Procedures}

School psychology graduate students were trained to mastery in the principles and procedures of $\mathrm{CBC}$ using competency-based training methods. Prior to beginning casework, students demonstrated mastery of $\mathrm{CBC}$ procedures by achieving an average of $85 \%$ of $\mathrm{CBC}$ interview objectives across two or more role 
plays. Further information on competency-based training procedures, structured interviews, and consultation casework are available in Kratochwill, Sheridan, Carrington Rotto, and Salmon (1991) and Sheridan (1992).

Students were referred for participation in the CBC process by school psychologists, administrators, and additional school staff. These referrals resulted from the presence of academic, behavioral, or socioemotional difficulties that interfered with their functioning and learning at home and/or school (e.g., off-task behaviors, work completion, noncompliance). Specific target behaviors were identified for each student at school and at home. At school, 71\% of the target behaviors were behavioral and $29 \%$ were academic. At home, $79 \%$ of the target behaviors were behavioral and $21 \%$ were academic.

CBC consultants followed a problem-solving model that consisted of four stages for all of their casework. Stages were conjoint needs identification, needs analysis, plan implementation, and plan evaluation (Sheridan \& Kratochwill, 2008; Sheridan et al., 1996). CBC was implemented with parents and teachers serving as coconsultees in the same meeting. The interviews followed a structured interview process using protocols available in published literature (Sheridan \& Kratochwill, 2008; Sheridan et al., 1996). All cases and interviews were coded for supervision and evaluation purposes.

\section{Integrity of $C B C$ Process}

Process integrity was measured by independent observers using the $\mathrm{CBC}$ Objectives Checklist to validate that consultation interviews were conducted in a manner consistent with the CBC model. All CBC cases were audiotaped and coded to determine adherence to each of the interview objectives. Across all consultants and interviews an average of $89 \%$ of the $\mathrm{CBC}$ objectives were obtained by consultants.

\section{Data Collection}

Audiotaped interviews of consultation cases were randomly assigned to a team of research members. Research members were school psychology graduate students who were previously trained in the CBC process and the use of the POM (Sheridan, Marti, et al., 2005). To meet mastery in the use of the POM, coders listened to sample interviews and then rated the consultant's use of the partnership-centered themes on the POM. Advanced graduate students with several years of research and practical experience in CBC trained coders in use of the POM, and ensured that coders reached $85 \%$ agreement with the master key.

The POM was used to code each partnership orientation theme demonstrated during the CBC process (see Appendix). Coders rated each principle based on the opportunities perceived to be present in the interview relative to opportunities utilized by the consultant. Coders were specifically instructed to rate the quality of the consultant's ability to convey a tone or climate reflective of the principle coded rather than the frequency of use. For each interview, partnership orientation scores could range from 7 to 42 . Ratings across interviews within a case were summed and then averaged to derive a total consultation case score. Consistent with the scaling of the POM, cases with a partnership orientation score below 2 were considered to be mostly ineffective at exhibiting partnership oriented themes. Cases with a partnership orientation score above 5 were considered to be mostly effective at illustrating partnership orientation themes.

Coders completed the coding task in two steps. First, they listened to the interview tape and determined if the consultant had the opportunity to use each of the 7 partnership orientation themes. They chose "yes" if the theme was present or "no" if the theme was absent on the coding worksheet based on opportunities present within the interview. Second, coders listened to the tape a second time. For each opportunity to demonstrate partnership oriented themes, coders rated the consultant's effectiveness as determined by their ability to convey a tone or climate reflective of the principle coded.

Coding guidelines were provided for the coders. Coders were instructed to code what they heard in the interview, not how they would have guided the interview as the consultant. In certain situations, a verbal statement could reflect more than one partnership theme (e.g., recommending a variety of intervention strategies based on the student's needs could be seen as resourceful and shares information and encourages) and were coded as such. Coding 
was based on the consultant's effectiveness in delivering the message, rather than the content or frequency of specific verbal statements.

\section{Interrater Agreement}

Interrater agreement checks were conducted on $33 \%$ of the interviews. Ratings were considered in agreement if they were within one effectiveness rating of one another on the Likert scale. For example, if one coder rated a partnership oriented theme with a 3 and another coder rated the same theme with a 4 , the ratings were considered to be in agreement. If one coder rated a partnership oriented theme with a 4 and the other coder rated the same theme with a 6, ratings were not in agreement. Using this criterion, interrater agreement was $100 \%$.

\section{Design and Data Analysis}

Regression analyses were conducted to determine the degree to which partnership orientation scores predicted the following CBC case outcomes: satisfaction, acceptability, perceived effectiveness, and effect sizes. Because the main interest with the aforementioned research questions was in arriving at a prediction equation for case outcomes, and it was reasonable to assume the consultant's use of partnership style preceded case outcomes, regression analyses were conducted (Keith, 2006). It was hypothesized that high levels of partnership orientation would be associated with positive case outcomes (i.e., percep- tions of acceptability, effectiveness, and satisfaction). Pearson product-moment correlation coefficient analyses were conducted to assess the relationship between partnership orientation and CBC process integrity. It was hypothesized that high levels of partnership orientation would be negatively correlated with integrity of the CBC process. Due to the directional nature of the hypothesis, one-tailed hypothesis tests were used.

\section{Results}

Table 2 presents the descriptive information (means and standard deviations) collected for each predictor and outcome variable. As seen in Table 2, similar patterns of acceptability, effectiveness, and satisfaction were found across scales and respondents. Specifically, mean scores demonstrated high acceptability of $\mathrm{CBC}$, perceptions of effectiveness of $\mathrm{CBC}$, and satisfaction with the consultant. POM scores demonstrated that, on average, consultants conducted CBC with a partnership orientation in a generally effective fashion.

\section{Research Question One: Does Partnership Orien- tation Predict Case Outcomes in CBC?}

Simple linear regression analyses were conducted to evaluate the prediction of each $\mathrm{CBC}$ case outcome variable (acceptability, effectiveness, and satisfaction) from partnership orientation scores. Results are

Table 2. Case Outcomes

\begin{tabular}{|c|c|c|c|c|c|c|c|c|}
\hline & \multicolumn{3}{|c|}{ BIRS-A $^{b}$} & \multicolumn{2}{|c|}{ BIRS-Ec } & \multicolumn{3}{|c|}{$\mathrm{CEF}^{\mathrm{d}}$} \\
\hline & $\mathrm{POM}^{\mathrm{a}}$ & Parent & Teacher & Parent & Teacher & Parent & Teacher & $\mathrm{ES}^{\mathrm{e}}$ \\
\hline$M$ & 4.04 & 5.48 & 5.36 & 4.69 & 4.55 & 6.44 & 6.30 & 0.988 \\
\hline$M d n$ & 3.86 & 5.65 & 5.6 & 4.79 & 4.79 & 6.54 & 6.54 & 1.12 \\
\hline$S D$ & 0.639 & 0.547 & 0.66 & 0.988 & 1.13 & 0.557 & 0.669 & 1.05 \\
\hline
\end{tabular}

POM = Partnership Orientation Measure; BIRS = Behavior Intervention Rating Scale; A = Acceptability; E = Effectiveness; CBC = conjoint behavioral consultation; $\mathrm{CEF}=$ Consultant Evaluation Form.

a Low $=1$, high $=6$. Mean item ratings on the POM, with high scores reflective of greater levels of partnership orientation.

$\mathrm{b}$ Low $=1$, high $=6$. Mean item ratings on the BIRC-A factor, with high scores reflective of greater levels of consultee acceptability of CBC.

$\mathrm{C}$ Low $=1$, high $=6$. Mean item ratings on the BIRC-E factor, with high scores suggestive of greater levels of consultee perception that $\mathrm{CBC}$ was effective at addressing needs.

$\mathrm{d}$ Low $=1$, high $=7$. Mean item ratings on the $C E F$, with high ratings indicating high levels of consultee satisfaction with the consultant and CBC process.

e Average effect size across cases, computed using a "no assumptions approach" (Busk \& Serlin, 1992). 
Table 3. Summary of Linear Regression Analyses of CBC Acceptability and Satisfaction on Partnership Orientation

\begin{tabular}{|c|c|c|c|c|}
\hline \multirow{3}{*}{$\begin{array}{l}\text { Partnership Orientation } \\
\text { Regression Results }\end{array}$} & \multicolumn{4}{|c|}{ Outcome Measures } \\
\hline & \multicolumn{2}{|c|}{ BIRS-A } & \multicolumn{2}{|c|}{ CEF } \\
\hline & Parent & Teacher & Parent & Teacher \\
\hline $\mathrm{B}(S E)$ & $-0.002(0.202)$ & $0.544(0.207)$ & $0.207(0.205)$ & $0.396(0.288)$ \\
\hline$\beta$ & -0.002 & $0.526^{*}$ & 0.031 & $0.379 *$ \\
\hline$R^{2}$ & -0.001 & 0.277 & 0.001 & 0.143 \\
\hline
\end{tabular}

$N=20$. BIRS-A = Behavior Intervention Rating Scale-Acceptability; CEF = Consultant Evaluation Form; $S E=$ standard error or level of precision in estimate and can be used to report the confidence intervals and test hypotheses.

${ }^{*} p<.05$ (determined significance based on one-tailed hypothesis).

presented in Table 3. Standard error scores that reflect the precision of analyses are also reported in Table 3. Two significant relationships were found. First, a significant linear relationship was evident between partnership orientation and teacher acceptability, $R$ $=.526 ; t(18)=2.627 ; p=.01$, suggesting that partnership orientation within CBC predicted teacher acceptability. For every 1-point increase in partnership orientation score, a 0.54 point increase in acceptability score can be expected. Approximately $28 \%$ of the variance of teacher acceptability scores can be accounted for by the degree of partnership orientation $\left(R^{2}=.277\right)$.

Second, a significant relationship was demonstrated between partnership orientation and teacher satisfaction, $R=.379 ; t(18)=1.736 ; p=.05$. Partnership orientation in $C B C$ was found to predict teacher satisfaction. For every 1-point increase in partnership orientation score, a 0.40 point increase in teacher satisfaction scores can be expected. Approximately $14 \%$ of the variance of teacher satisfaction scores can be accounted for by the degree of partnership orientation $\left(R^{2}=.143\right)$. Partnership orientation did not predict parent acceptability or satisfaction of CBC. Partnership orientation also did not predict teacher or parent perceptions of effectiveness, or case effect sizes.

Research Question 2: What is the Relationship Between Partnership Orientation and the Integrity of the CBC Problem-Solving Process?

A Pearson product-moment correlation coefficient analysis was computed to determine the relationship between partnership orientation and CBC process integrity. It was hypothesized that high lev- els of partnership orientation would be negatively correlated with integrity of the CBC process. Results indicated no significant correlation between the integrity of the CBC process and partnership orientation scores. Across interviews, $89.28 \%$ of CBC objectives were met. Integrity scores across consultants and interviews were high (range $=81.56$ to $98.13 \%$ ). In general, the results suggest that conducting CBC sessions with integrity is unrelated to a partnership orientation. Thus, a high degree of integrity for consultation meeting objectives may be maintained while also incorporating partnership-oriented themes.

\section{Discussion}

\section{Main Findings}

This is the first study to investigate the effectiveness of a partnership orientation within CBC. The current study furthered previous research, which has identified effective partnerships as being correlated with improvements in students' academic, social, and behavioral functioning. The purpose of this study was twofold: to investigate the degree to which $\mathrm{CBC}$ as a partnership model predicts social validity of the CBC process and case outcomes; and to identify the relationship between partnership orientation and integrity of the CBC process. There are a number of important findings and associated implications for research and practice. In addition, limitations and directions for future research are presented.

A partnership orientation was significant at predicting teachers' acceptability of and satisfaction with $\mathrm{CBC}$. This finding suggests that a higher 
level of partnership orientation may create conditions for teachers to view families in a collaborative context with opportunities for shared roles and responsibilities in educating children. Similarly, teachers may acknowledge the unique expertise families bring forth and therefore, both parties are likely to defer to each other's judgments and expertise as appropriate (Turnbull, Turnbull, Erwin, \& Soodak, 2006). A partnership orientation may provide the prerequisite conditions (i.e., approach, atmosphere, and attitudes) for collaborative actions on behalf of educators (Christenson \& Sheridan, 2001). It is also possible that partnering with parents may address common teacherreported barriers, such as different backgrounds, time constraints, and parents' lack of understanding (Gettinger \& Guetschow, 1998).

Parents' acceptability and satisfaction with the CBC process were not predicted by partnership orientation. There are some possible explanations for this finding. First, parents routinely describe the $\mathrm{CBC}$ experience very favorably as evidenced by their high acceptability and effectiveness ratings (Sheridan et al., 2001; Sheridan \& Steck, 1995; Sladeczek et al., 2006). It may be that the degree to which a partnership "tone" is projected may be less important to parents' ratings of acceptability and satisfaction than their sheer inclusion in the problem-solving and decision-making process. It could be that $\mathrm{CBC}$ is experienced by parents in a manner that is distinct from other forms of traditional parent involvement. For example, the structure of parent-teacher conferences traditionally has not allowed for parents to take an active role. However, in CBC parents are provided the opportunity to assume an active role, which in and of itself may relate to acceptability and satisfaction.

A partnership orientation did not significantly predict child outcomes. This suggests that a partnership orientation, although important, may not be sufficient to account for child outcomes. CBC is a structured process within which evidence-based interventions can be developed and implemented (Frank \& Kratochwill, 2008) and the range of interventions developed and implemented in CBC likely explains some of the variance associated with child outcomes.

Finally, there were no significant relationships between the integrity of the CBC process and a partnership orientation. Thus, it appears that the integ- rity of the problem-solving objectives of $\mathrm{CBC}$, which include an emphasis on data-based decision-making, may be retained even within a partnership-oriented practice. Although these results cannot infer causality, there is promising evidence to suggest $\mathrm{CBC}$ consultants may be able to use a problem-solving model in a technically sound manner while retaining a partnership-orientation framework.

\section{Implications}

Results of this study revealed that teachers appear to value partnering with families, which provides further support for school psychologists and educators to continue finding ways to enhance family school partnerships. Moreover, CBC implemented within a partnership orientation may provide teachers with collaborative experiences in school settings. Administrators as well as teachers may be advised to advocate for and encourage school personnel to partner with families.

The current study found that families' acceptability and satisfaction with CBC were not predicted by a partnership orientation; however, parents have routinely described the CBC process very favorably (e.g., Sheridan et al., 2001). This finding may reveal that the partnership "tone" conveyed to families is not as important as simply being included in the process; therefore, efforts with families should focus on moving from basic levels of involvement to embodying an active partnership role. In achieving this goal, it is important to give critical attention to the ways parents are involved in schools. Additionally, it will be important to consider the message conveyed to parents with different types of involvement. For example, if families are only involved in ways that allow for one-directional communication, they may not feel apt to partner with schools in the future and may lack confidence in their skills and knowledge. Increasing the quality and amount of responsibility that is given to families may increase their stake in their child's school and education. In $\mathrm{CBC}$, parents are encouraged to be equal stakeholders and decision makers; other areas of school involvement should focus on ensuring this kind of equity is established.

Partnership-building should remain an integral part of preservice education especially considering that increases in the level of partnership does not 
negatively affect the fidelity of the problem-solving model. Increased legislative initiatives and empirical studies advocating for family school partnerships have led to an increase in the emphasis on family school partnerships in preservice education programs (Sheridan, Cowan, \& Eagle, 2000). CBC combines the efficacy of a problem-solving model and family school partnerships; however, heretofore the effect of combining the two was not known. Results reveal that, in fact, a problem-solving model can be implemented with high fidelity and simultaneously build effective partnerships.

\section{Limitations and Future Directions}

There are many important findings yielded by the current study. Included along with those findings are limitations that should be taken into consideration when interpreting the results. In addition, because of the exploratory nature of the current investigation there are many directions through which the current study can be extended.

First, graduate students served as consultants in all of the cases that comprised this study. As such, they were involved in identical, rigorous, and systematic training procedures in $\mathrm{CBC}$, which may indicate that the sample used in this study was somewhat restricted. These training conditions may not be the same as those experienced outside of preservice education programs; thus, the external validity and the extent to which the findings can be generalized to other settings may be questionable.

A second, related limitation of the current investigation refers to the small sample size and lack of experimental manipulation. Future research should focus on including a larger sample and random assignment to experimental and control conditions to increase reliability and generalizability of the findings. Increasing the sample size will also lead to greater statistical power in interpreting the results, thus increasing the confidence with which the findings may be interpreted. Moreover, the substantial range restriction may have attenuated the variables explored in this study. Specifically, the overall and relative influence of the variables explored herein may have been diminished due to the restricted range.

Third, parents and teachers consistently reported high levels of acceptability, satisfaction, and per- ceived effectiveness in this study, which resulted in a lack of variability in the social validity outcome data. Because of the lack of variability, the possibility of making a Type I or Type II error exists. Next, effect sizes in the current study were calculated on a case-by-case basis using a "no assumptions" approach (Busk \& Serlin, 1992). This method for computing effect sizes may have led to inflated effect sizes (relative to conventional standards for interpreting effect sizes; Cohen, 1988) with a high degree of variability. There currently appears to be an absence of an agreed upon approach for calculating and interpreting effect sizes in small $n$ research (Parker \& Bossart, 2003). It would do the field well to continue pursuing a reliable and effective method for calculating effect sizes in single case, school-based research when relatively few data points are available.

Fourth, further research is needed to control for and thus explain the influence of the range of interventions implemented during the $\mathrm{CBC}$ process. This will yield a better understanding of the relative effects $C B C$ on case outcomes. Although $C B C$ is a structured process through which evidence-based interventions can be developed and implemented, the relative influence of the $\mathrm{CBC}$ process is not clear given the variability of interventions that are implemented on a case-by-case basis. As such, controlling for the type of intervention would allow for a more thorough understanding of CBC's influence on case outcomes. Some research using experimental small- $n$ designs have begun to explore the differential benefits of CBC over other models (teacher consultation; self-administered manuals) using standard interventions (e.g., Galloway \& Sheridan, 1994; Sheridan et al., 1990) with encouraging results. Large scale empirical research is now needed to validate these findings.

Fifth, in addition to further investigating characteristics of the CBC consultation process (e.g., the range of interventions), it would also be helpful to provide a better understanding for the relative influence individuals and the experience they bring to the consultation process has on case outcomes. Specifically, analyzing results across the level of consultant training and experience and/or the level of teacher experience would allow for a consideration of additional qualities individuals bring to consultation meetings, and thus might aid in providing a more thorough explanation for the results. 
Sixth, more research is needed on psychometric properties of several of the instruments involved in this study. Specifically, the POM is in need of further investigations to assess its psychometric properties; however, it appears to be an instrument that may be helpful in assessing the level of partnership orientation in existing models and aiding in the development of future partnership-oriented models. Future research in this area could focus on conducting factor analyses, more comprehensive internal consistency estimates, and comparing its internal consistency with other scales designed to measure similar constructs. In addition to factor analyses and internal consistency evaluations, the external validity of the measure should also be explored. The initial content validity assessment of the POM reveals that it is representative of a partnership orientation. Future investigations should focus on evaluating validity of the POM using greater breadth and precision.

Finally, and related to the psychometric issues of the POM, it is the case that many of the measures used in consultation research lack evidence for content and construct validity, despite their use in over decades of research. For example, the external validity of the BIRS has not been investigated. Research in the field has failed to pose measurement advances on scales assessing important social validity indices. Measures such as the BIRS-R and CEF have great utility for assessing satisfaction within the consultation process. Thus, it is timely for consultation research to advance the psychometric rigor of the measurement tools commonly used in the field.

\section{References}

Adams, K. C., \& Christenson, S. L. (2000). Trust and family-school relationship: Examination of parent-teacher differences in elementary and secondary grades. Journal of School Psychology, 38, 477-497.

Busk, P. L., \& Serlin, R. C. (1992). Meta-analysis for single-case research. In T. R. Kratochwill \& J. R. Levin (Eds.), Single-case research design and analysis: Applications in psychology and education (pp. 187-212). Hillsdale, NJ: Erlbaum.

Christenson, S. L., Rounds, T., \& Franklin, M. (1992). Home-school collaboration: Effects, issues, and opportunities. In S. Christenson \& J. Conoley (Eds.), Home-school collaboration (pp. 19-51). Silver Spring, MD: National Association of School Psychologists.
Christenson, S. L., \& Sheridan, S. M. (2001). Schools and families: Creating essential connections for learning. New York: Guilford.

Cohen, J. (1988). Statistical power analysis for the behavioral sciences (2nd ed.). Hillsdale, NJ: Erlbaum.

Colton, D., \& Sheridan, S. M. (1998). Conjoint behavioral consultation and social skills training: Enhancing the play behavior of boys with attention deficit-hyperactivity disorder. Journal of Educational and Psychological Consultation, 9, 3-28.

Dunst, C., Trivette, C., \& Deal, A. (Eds.). (1994). Supporting $\mathcal{E}$ strengthening families: Methods, strategies and practices (Vol. 1). Cambridge, MA: Brookline.

Elliott, S. N., \& Von Brock Treuting, M. (1991). The Behavior Intervention Rating Scale: Development and validation of a pretreatment acceptability and effectiveness measure. Journal of School Psychology, 29, 43-51.

Erchul, W. P. (1987). A relational communication analysis of control in school consultation. Professional School Psychology, 2, 113-124.

Erdfelder, E., Faul, F., \& Buchner, A. (1996). GPOWER: A general power analysis program. Behavior Research Methods, Instruments, \& Computers, 28, 1-11.

Frank, J. L., \& Kratochwill, T. R. (2008). School-based problem-solving consultation: Plotting a new course for evidence-based research and practice in consultation. In W. P. Erchul \& S. M. Sheridan (Eds.), Handbook of research in school consultation: Empirical foundations for the field. Mahwah, NJ: Erlbaum.

Galloway, J., \& Sheridan, S. M. (1994). Implementing scientific practices through case studies: Examples using home-school interventions and consultation. Journal of School Psychology, 32, 385-413.

Gettinger, M., \& Guetschow, K. W. (1998). Parental involvement in schools: Parent and teacher perceptions of roles, efficacy, and opportunities. Journal of Research and Development in Education, 32, 38-52.

Guli, L. A. (2005). Evidence-based parent consultation with school-related outcomes. School Psychology Quarterly, 20, 455-472.

Hess, R. D., \& Holloway, S. D. (1984). Family and school as educational institutions. In R. D. Parke, R. M. Emde, H. P. McAdoo, \& G. P. Sackett (Eds.), Review of Child Development Research: Vol. 7. The family (pp. 179222). Chicago: University of Chicago Press.

Illsley, S. D., \& Sladeczek, I. E. (2001). Conjoint behavioral consultation: Outcome measures beyond the client level. Journal of Educational \& Psychological Consultation, 12, 397-404.

Keith, T. Z. (2006). Multiple regression and beyond. Boston: Pearson Education.

Kellaghan, T., Sloane, K., Alvarez, B., \& Bloom, B. S. (1993). The home environment and school learning: Pro- 
moting parental involvement in the education of children. San Francisco: Jossey-Bass.

Kratochwill, T. R., Elliott, S. N., Loitz, P. A., Sladeczek, I. E., \& Carlson, J. (2003). Conjoint consultation using self-administered manual and videotape parentteacher training: Effects on children's challenging behaviors. School Psychology Quarterly, 18, 269-302.

Kratochwill, T. R., Sheridan, S. M., Carrington Rotto, P., \& Salmon, D. (1991). Preparation of school psychologists to serve as consultants for teachers of emotionally disturbed children. School Psychology Review, 20, 530-549.

McWilliam, R. A., Maxwell, K. L., \& Sloper, K. M. (1999). Beyond "involvement:" Are elementary schools ready to be family-centered? School Psychology Review, 28, 378-394.

Noell, G. H. (2008). Research examining the relationships among consultation process, treatment integrity, and outcomes. In W. P. Erchul \& S. M. Sheridan (Eds.), Handbook of research in school consultation: Empirical foundations for the field. Mahwah, NJ: Erlbaum.

Parker, R. I., \& Bossart, D. F. (2003). Evaluating singlecase research data: A comparison of seven statistical methods. Behavior Therapy, 34, 189-211.

Ray, K. P., Skinner, C. H., \& Watson, T. S. (1999). Transferring stimulus control via momentum to increase compliance in a student with autism: A demonstration of collaborative consultation. School Psychology Review, 28, 622-628.

Sheridan, S. M. (1992). Consultant and client outcomes of competency-based behavioral consultation training. School Psychology Quarterly, 7, 245-270.

Sheridan, S. M., Clarke, B. L., \& Burt, J. D. (2008). Conjoint behavioral consultation: What do we know and what do we need to know? In W. P. Erchul \& S. M. Sheridan (Eds.), Handbook of research in school consultation: Empirical foundations for the field. Mahwah, NJ: Erlbaum.

Sheridan, S. M., \& Colton, D. L. (1994). Conjoint behavioral consultation: A review and case study. Journal of Educational and Psychological Consultation, 5, 211-228.

Sheridan, S. M., Cowan, R. J., \& Eagle, J. W. (2000). Partnering with parents in educational programming for student with special needs. In C. Telzrow \& M. Tankersley (Eds.), IDEA amendments of 1997: Practice guidelines for school-based teams (pp. 307-349). Bethesda, MD: National Association of School Psychologists.

Sheridan, S. M., Eagle, J. W., Cowan, R. J., \& Mickelson, W. (2001). The effects of conjoint behavioral consultation: Results of a four-year investigation. Journal of School Psychology, 39, 361-385.

Sheridan, S. M., Eagle, J. W., \& Dowd, S. E. (2005). Families as contexts for children's adaptation. In S. Goldstein \& R. Brooks (Eds.), Handbook of resil- ience in children (pp. 165-179). New York: Kluwer Academic/Plenum.

Sheridan, S. M., \& Kratochwill, T. R. (2008). Conjoint behavioral consultation: Promoting family-school connections and interventions. New York: Springer.

Sheridan, S. M., Kratochwill, T. R., \& Bergan, J. R. (1996). Conjoint behavioral consultation: A procedural manual. New York: Plenum.

Sheridan, S. M., Kratochwill, T. R., \& Elliott, S. N. (1990). Behavioral consultation with parents and teachers: Delivering treatment for socially withdrawn children at home and school. School Psychology Review, 19, 33-52.

Sheridan, S. M., Marti, D. C., Clarke, B. L., Burt, J. D., Black, K. A., Rohlk, A. M., et al. (2005, March). Is conjoint behavioral consultation partnership centered? An exploratory analysis. Paper presented at the annual conference for the National Association of School Psychologists, Atlanta, GA.

Sheridan, S. M., Meegan, S. P., \& Eagle, J. W. (2002). Assessing the social context in initial conjoint behavioral consultation interviews: An exploratory analysis investigating processes and outcomes. School Psychology Quarterly, 17, 299-324.

Sheridan, S. M., \& Steck, M. C. (1995). Acceptability of conjoint behavioral consultation: A national survey of school psychologists. School Psychology Review, 24, 633-647.

Sheridan, S. M., Warnes, E. D., Cowan, R. J., Schemm, A. V., \& Clarke, B. L. (2004). Family-centered positive psychology: Focusing on strengths to build student success. Psychology in the Schools, 41, 7-17.

Sladeczek, I. E., Madden, L., Illsley, S. D., Finn, C., \& August, P. J. (2006). American and Canadian perceptions of the acceptability of conjoint behavioral consultation. School Psychology International, 27, 57-77.

Trivette, C. M., \& Dunst, C. J. (1994). Helpgiving practices scale. Asheville, NC: Winterberry.

Turnbull, A. P., Turnbull, H. R., Erwin, E., \& Soodak, L. (2006). Professionals, families, and exceptionality: Enhancing outcomes through partnerships and trust (5th ed.). Upper Saddle River, NJ: Merrill/Prentice Hall.

Walberg, H. J. (1984). Families as partners in educational productivity. Phi Delta Kappan, 65, 397-400.

Weiner, R., Sheridan, S. M., \& Jenson, W. R. (1998). Effects of conjoint behavioral consultation and a structured homework program on math completion and accuracy in junior high students. School Psychology Quarterly, 13, 281-309.

Wilkinson, L. A. (2005). An evaluation of conjoint behavioral consultation as a model for supporting students with emotional and behavioral difficulties in mainstream classrooms. Emotional and Behavioural Difficulties, 10, 119-136. 
Appendix A. Partnership Orientation Theme Definitions

Partnership Orientation Theme

Focuses on Strengths

Promotes Teaming and Collaboration

Encourages

Is Sensitive and Responsive

Uses Effective Communication

Promotes Skill Development

Is Resourceful and Shares Information
Definition

The consultant emphasizes and identifies positive qualities and characteristics of the family, teacher, and child. The consultant:

- Views family, teacher, and child in a positive light

- Focuses on family, teacher, and child strengths rather than weaknesses

- Responds to strengths of family, teacher, and child The consultant works jointly with the family and the teacher by identifying strengths, needs, and goals. The consultant incorporates family and teacher input into data collection and plan development. Additionally, the consultant promotes a shared responsibility and ownership for the student. The consultant:

- Identifies priorities in a joint, collaborative fashion

- Establishes collaborative networks

- Emphasizes a team concept

- Asks family and teacher to work with them The consultant responds to the family and teacher in a way that promotes and inspires family and teacher decision-making in the consultation process. The consultant:

- Encourages family and teacher to speak up for the child

- Encourages family and teacher to make their own decisions

- Encourages family and teacher to use their capabilities and knowledge to get resources

- Consultant provides a choice about whether or not family and teacher want to plan to do things at home with the child

The consultant asks questions or makes statements that demonstrate an awareness of the needs, attitudes, and feelings of the family and teacher. The consultant is empathetic and responds positively to the family and teacher. The consultant:

- Focuses on family, teacher, and child needs without being critical

- Acknowledges different perspectives

- Is friendly and supportive of the family and teacher

- Makes changes when the family and teacher ask for things

- Checks to make sure the family and teacher are happy

- Has a good understanding of family and teacher values and displays an interest in learning even more about the family and teacher

- Is honest and sincere; tries to understand concerns; seems warm and caring with family and teacher

The consultant utilizes effective communication strategies to guide the consultation process and to promote clear understanding for the consultant, family, and teacher. Examples of effective communication strategies include: asking open-ended questions, eliciting examples, using minimal encouragers, paraphrasing (restating someone's statements to check for accuracy), clarifying (asking someone to explain his or her statement more clearly), reflecting (repeating the emotional message behind a statement) (DeBoer, 1995). The consultant:

- Uses clear communication when telling family and teacher their concerns and suggestions

- Checks to make sure family and teacher understand

The consultant promotes new and existing family and teacher abilities. This can include explaining and/or modeling steps in the problem-solving process (e.g., defining a priority need, collecting information, setting goals, and monitoring and evaluating progress) as well as describing, training, modeling, and reinforcing specific techniques and interventions. The consultant:

- Promotes family, teacher, and child skills and competencies

- Helps the family and teacher learn skills to get resources to meeting their needs

- Helps develop family, teacher, and child abilities

The consultant locates and communicates additional resources, options, and opportunities available to the family and teacher. The consultant provides information pertinent to the case (e.g., rating scales, observation data, and developmental information). The consultant:

- Provides many choices to the family and teacher

- Provides information about the resources and options that are available to family and teacher

- Provides useful suggestions

- Helps family and teacher find solutions to problems 